\title{
Insider Perspectives vs. Public Perceptions of ICT: toward policy for enhancing female student participation in academic pathways to professional careers in ICT
}

\author{
LYN COURTNEY, COLIN LANKSHEAR, \\ NEIL ANDERSON \& CAROLYN TIMMS \\ James Cook University, Cairns, Queensland, Australia
}

\begin{abstract}
This article reports findings of a national online survey of Australian women employed in Information and Communication Technology (ICT)-related careers. The Women in ICT Industry Survey was the culminating stage of a larger Australian Research Council Linkage Grant project investigating factors associated with low and declining female participation rates in professional-level ICT pathways. The survey comprised a mix of forced-choice and open-ended short-response items, and was completed by 272 Australian women. Application of K-means cluster analysis to forced-choice item responses revealed three discrete groupings of female ICT professionals. Overall, respondents reported that their ICT career was rewarding, provided opportunities and challenges, and was beneficial to society. Respondents generally disagreed with Queensland high school girls' perceptions that ICT is boring, sedentary, and not relevant to their future career directions. They also disagreed that the industry fits the prevailing negative stereotype of being populated by 'geeks' and 'nerds'. Divergent opinions centered mainly around participants' confidence in their own technical ability, whether they would encourage young women to enter the ICT industry, and how they perceived and responded to industrial issues of equality and management approachability. These findings support suggestions for a range of policy and curriculum initiatives designed to enable more positive experiences of computing in school, and to optimize ICT career pathways in tandem with furthering wider educational ends.
\end{abstract}

\section{Introduction}

This article reports findings from an Australia-wide online survey conducted during 2006 of professional women working in the Information and Communication Technology (ICT) industry (Anderson et al, 2006; Courtney et al, 2006, 2007; Timms et al, 2006). The survey formed part of a larger Australian Research Council (ARC) Linkage Grant project undertaken by the project team in partnership with the government agency Education Queensland (EQ) and a local company, Technology One. The project investigated low participation rates of females in pathways to professional-level ICT occupations and aimed to inform development of evidence-based strategies to increase the number of young women participating in educational pathways leading to professional careers in ICT. The survey of women ICT professionals elicited information on two themes. The first involved respondents' retrospective perceptions and experiences of ICT during high school. The second involved their experiences of ICT as a career and their current attitudes toward their career. This article focuses on the second theme.

ICT continues to reach more deeply into everyday life and exerts greater influences on daily routines at work and home. Yet, many Western countries are struggling to recruit sufficient 
numbers of people for professional-level ICT careers and within other employment sectors that rely heavily on this technology (e.g. finance, higher education that requires specialists for programming). The Australian government recently listed 47 professions on the Migration Occupations in Demand List (Department of Immigration and Citizenship, 2007), 10 of which were professional computer specialists (e.g. Java, network security, Sybase SQL Server). Formal education cannot currently provide graduates fast enough to meet the increasing demands for skilled ICT professionals (Zweben \& Aspray, 2004; Australian Bureau of Statistics, 2006). In 2006, the ABS cited the proportion of women workers within the ICT industry as $16 \%$, with only $3 \%$ of electronic engineers and communication technicians being women. As most professional jobs in ICT require an advanced degree in this field, female representation in ICT academic programs provides the key gateway for access into these careers. Consequently, low and falling levels of participation by female students in ICT courses exacerbate failure to meet existing and projected labor requirements, and help contribute to shortfalls in the first place (Newmarch et al, 2000; Margolis \& Fisher, 2003; Coonan, 2005a; Griffiths et al, 2008).

This downward trend is evident in the United States, where there was a decline in females graduating with computer science bachelor degrees from $51 \%$ of the graduate cohort in 1992 to $40 \%$ in 2002 (National Science Foundation, 2002). Charles \& Bradley (2006) utilized a relatively new dataset from the Organisation for Economic Co-operation and Development (2004) to investigate female underrepresentation in computer science tertiary programs across 21 industrialized countries in 2001. These countries included Australia, most European countries, New Zealand, three former Soviet states, Turkey, Korea, the United Kingdom, and the USA. Their findings confirmed that women were underrepresented in ICT academic programs in all 21 countries with considerable cross-national variability in the amount of male overrepresentation. They attributed the large variability directly to socialization and cultural stereotypes of genderspecific career aspirations, which tended to undermine female participation in traditionally male academic programs (Ridgeway \& Correll, 2004).

Of equal concern was the disproportionate attrition of females in computer science majors revealed by two studies conducted in the US state of Virginia during 1992 to 1997 and 2001 by Cohoon $(1999,2001,2006)$. These concluded that changes in attitudes and behavior by faculty (e.g. providing more faculty support and encouragement) could ameliorate female attrition. Similarly, in Australian tertiary institutions, female participation in ICT degrees fell from $26.2 \%$ in 1989 to $19 \%$ in 2000 (Newmarch et al, 2000). The number of female students in Australian universities increased by $1.6 \%$ from 2003 to 2004 , yet the number of females participating in ICT degrees decreased by $14.7 \%$ in the same year (Coonan, 2005b).

Corresponding trends of low participation rates in ICT courses are notable in secondary school. For example, in the Australian state of Queensland, female enrolments in the Year 11 and 12 advanced ICT Board subject Information Processing and Technology fell from 30\% in 1997, when the subject was first introduced, to $18 \%$ in 2006 (Queensland Studies Authority, 2007) (see Figure 1).

Low female participation rates in ICT professional careers is both an equity issue, when viewed from the standpoint of female participation, and a pragmatic issue, with potentially far-reaching implications for the competitive advantage of organizations, countries and regional economic blocs (Woodfield, 2002; Oudshoorn et al, 2004; Frieze, 2005). Women miss opportunities to participate in a highly skilled, well-remunerated, challenging job market and to experience the status and satisfaction that come from career advancements in this field. Equally, acute underrepresentation of women in the ICT sector undermines its economic efficiency and potential for growth. Organizations that can anticipate, accommodate, and satisfy requirements of consumers effectively are most likely to prosper (Department of Communications, Information Technology and the Arts, 2006). Moreover, social diversity is underrepresented in the ICT sector as the perspectives of female consumers of ICT are frequently overlooked or poorly understood in product conception and design. Consequently, frustrations alienate many consumers from the sector, which can impede further growth and generate economic inefficiencies (Woodfield, 2002; Oudshoorn et al, 2004). 


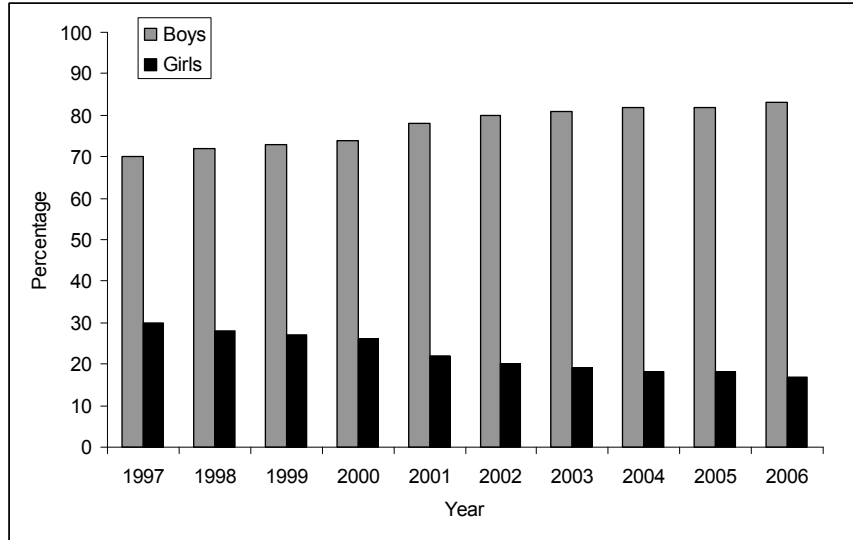

Figure 1. Years 11 and 12 enrolment numbers in the Board subject Information Processing and Technology from 1997 to 2006.

\section{Perceptions of ICT Careers and the ICT Industry: subjective origins of aversion}

Prior to surveying Australian women involved in ICT professional-level work, the research team had sampled opinion among Queensland female students in their last 2 years of high school. Information was obtained from 1500 participants by means of survey $(n=1452)$ and focus groups $(n=48)$ (Anderson et al, 2006). A prevalent view among those who offered opinions was that ICT subjects involved heavily constrained tasks that offered little opportunity for challenge and creativity. Non-takers of advanced ICT subjects maintained an overwhelmingly negative perception of ICT as being boring, too difficult and irrelevant to their career aspirations (Timms et al, 2006; Courtney et al, 2007). Often cited by these girls was: 'I'm not interested in computers' and 'I'd rather work with people rather than computers', which paralleled findings of Rommes et al's (2008) study into Dutch adolescents.

Similarly, a recent interview-based survey commissioned by the British Computer Society (2005) questioned girls aged 13 to 17 years about their computer usage rates, what they used computers for, and what reasons they provided for not choosing ICT as a profession. Despite $65 \%$ of respondents saying they found ICT lessons at school either very enjoyable or quite enjoyable, only $25 \%$ said they would consider a career in ICT. The main reason for not choosing an ICT career was having a preferred alternative, followed by not being interested in computers, and thinking the career boring. When asked what they associated with an ICT career the most frequent response (24\%) was 'do not know', followed by office work (17\%), secretarial/typing (17\%) and word processing $(11 \%)$. The main influence on choice of career was identified as parents $(49 \%)$, with teachers $(8 \%)$ ranking next.

The influence of parents/caregivers on career choice is especially interesting in light of widespread negative public perceptions of the ICT work culture as aversive for females (Meyerson \& Fletcher, 2000; Millar \& Jagger, 2001; Von Hellens \& Nielsen, 2001; Cuny \& Aspray, 2002; Trauth, 2002; Armstrong, 2005). Moore et al (2005) described women's experiences of the ICT workplace as a masculinized domain where women were either directly excluded from important decision making processes or indirectly excluded as a consequence of many decisions being made at the pub (bar) or, as suggested by Von Hellens \& Nielson (2001), at sporting events. Insufficient or inaccurate knowledge about ICT careers is cited as a further reason for girls and young women not taking this route (Young, 2002). Further barriers cited in the literature include perception of the ICT profession as demanding, not conducive to attaining a good balance between work and family, and not providing sufficient positive role models (Jepson \& Perl, 2002).

The negative image of the ICT industry is remarkably similar to the bad image of some of its most profitable and popular products and services. For example, video games and the Internet are often caricatured in terms of violence, pornography and predatory behavior. This negative portrayal may impact forcefully on young women arriving at significant career choice junctures, 
particularly if their parents/caregivers subscribe to similar perceptions, thus contributing to their reluctance to enter this profession.

\section{The Survey in Context}

Activists seeking to encourage girls and women to consider pursuing ICT professional-level careers have argued that the prevailing public perception is fallible. As part of its advocacy work in pursuit of better representation of women in study programs and careers in mathematics, science, engineering and ICT, the American Association of University Women Educators (2000) advocated active intervention to redress this imbalance.

Change the public face of computing. Make the public face of women in computing correspond to the reality rather than the stereotype. Girls tend to imagine that computer professionals live in a solitary, antisocial, and sedentary world. This is an alienating - and incorrect - perception of $[\mathrm{ICT}]$ careers ... (p. xii)

Against the broad background of an aversive industry image and calls to redress an image balance with respect to women's career experiences, the Women in ICT Industry Survey reported here sought information pertaining to four recurring research findings from international settings about girls' knowledge and images of the ICT industry:

- The ICT work culture is unappealing to women (Moore et al, 2005).

- The ICT sector is 'nerdy' (Margolis \& Fisher, 2003; Beyer \& DeKeuster, 2006).

- Female school students often have insufficient or inaccurate knowledge about ICT careers (Kahle \& Schmidt, 2004).

- The demands of ICT professional careers undermine a good balance between work and family life (Jepson \& Perl, 2002).

The survey was designed to tap participants' experiences germane to such perceptions.

\section{Study Aim and Purposes}

The immediate research aim was to map and attempt to understand insider perspectives in relation to outsider public perceptions of ICT careers and the ICT industry. The key questions concerned the relationships between survey respondents' experiences and perceptions of their careers and widely subscribed public images and perceptions of ICT careers and industry. These public images and perceptions constitute important elements of contexts within which female high school students make decisions about study options and future careers; decisions in which the great majority of girls reject ICT. By appealing to insider perceptions and, in particular, by making recourse to open-ended survey response items that provided indications of respondents' experiences, attitudes and perceptions in relation to specific items, the research was designed to contribute to four main purposes.

The first purpose was to provide a local index of the corrigibility of stereotypes and public perceptions across a broad spectrum of insider experiences. This is not to say that any particular female student would end up having similar experiences and perceptions were they to have opted to pursue an ICT career rather than rejecting it. It is, however, to imply that many of them might well do.

The second purpose was to begin developing a picture of 'reality on the ground' inside ICT careers relative to specific beliefs expressed by Queensland students. The Women in ICT survey instrument was developed in light of students' responses to the Girls and ICT Survey and views expressed in subsequent focus groups. It was hoped that findings based on the women's survey might usefully inform initiatives to enhance career-related decision making by students like those who participated in the study.

Third, the researchers sought to explore whatever diversity and complexity might exist within a substantially large population of respondents and capture any inflections evident among groups of respondents, rather than simply averaging aggregated responses and treating insider perspectives as though they were homogenous. This kind of subtlety, or complexity, may help stakeholders 
develop more sophisticated strategies and responses to conditions and factors they identify as problematic.

Fourth, by using survey items that were similar or identical to items that have been used in other national and international studies, the researchers hoped to contribute to possibilities for comparisons across contexts and over time.

The first three of these purposes are most relevant to this article.

\section{Methodology}

The Women in ICT Industry Survey was an Australia-wide, online survey which was active between May and October 2006. Remark Web Survey (Version 3: Professional) was used to design the survey, which allowed for the exportation of survey responses to Statistical Package for the Social Sciences (SPSS) for data analysis.

This article reports the survey findings at the initial stage of analysis; the survey respondents as an entire group. Subsequent publications will address the responses from participants working in specific areas of the ICT industry in order to make comparisons across sectors. The latter will include discussion of the extent to which features that recur across comparisons might be considered to be elements of an ICT 'culture' and/or of Australian women ICT professionals' responses as a whole to any such culture.

\section{Participants}

The online survey was completed by 272 women who self-identified as ICT professionals. Participants from all Australian states and territories responded. The survey adopted broad parameters for its target population to cover ICT professionals, ICT industry, industries/enterprises employing women in ICT professional-level roles. However, professional ICT women's associations were specifically targeted, as noted in the Procedure section below. By seeking information in the survey on the kind of work done by participants, and the industry sector within which they worked, the researchers anticipated being able to make successive refinements to analysis for purposes of specificity and comparison.

\section{Materials}

The survey design consisted of multiple question types intended to elicit quantitative data that could be treated statistically, as well as more qualitative data in the form of written responses to open-ended questions that allowed respondents to elaborate on particular items addressed in the survey. The questionnaire comprised 75 items, all but eight being closed questions. The eight openended questions sought responses of up to 250 characters and were interspersed at carefully chosen points throughout the survey.

The items were arranged in three sections, all of which used a mixture of open and closed (5point Likert-scale) questions. The first section sought demographic information such as age range, level of educational attainment and occupational information. The second section gathered retrospective information about the participants' high school experiences of ICT. The third section sought information about why respondents chose a career in ICT and about their experiences and perceptions of the ICT industry. In addition to open-ended questions and 5-point Likert-scale items, this section included a bank of five questions with a nominal scale: 'yes', 'no', 'unsure'. Some items were adapted from surveys of similar populations conducted in other studies (Young, 2002; Griffiths \& Moore, 2006).

Open-ended items typically appeared after a forced-choice question and were designed to allow respondents to elaborate on their experiences or perceptions. Four of the open-ended questions were with respect to the respondents' high school experiences with ICT and are not the focus of this article. The remaining four open-ended questions (see Table I) were designed to capture the respondents' reasons for choosing a career in ICT and their experiences working in the ICT profession. The responses were subjected to content analysis and to ensure reliability they were coded by two independent coders as suggested by Weber (1990). 


\begin{tabular}{ll}
\hline Section & Question \\
\hline C2 & Are there any other reasons that you chose ICT as your career? \\
C5 & If there are other qualities which you attribute to ICT as a career for women, please comment. \\
C8 & Please comment on what you would tell a young woman/girl about to enter the ICT industry. \\
C9 & If you have contemplated leaving the ICT industry - what are your reasons? \\
\hline
\end{tabular}

Table I. Open-ended questions.

\section{Procedure}

Participants were sought by a request in the Australian Business Review Weekly (27 July to 2 August 2006), through James Cook University press releases and by email to ICT companies (e.g. IBM; Technology One; Mincom); universities (e.g. Queensland University of Technology; Griffith University); government agencies (e.g. EQ; Department of Education, Science and Technology) and professional ICT organizations (e.g. Australian Women in IT and Science Entity; Women in Technology). A short introduction to the research aims, an invitation to participate and the website address were provided. Some organizations posted a notice about the survey on their homepage while other organizations announced the survey via newsletter or membership email. Once logged onto the website, an Information Sheet and Informed Consent Form were provided. Upon consent acceptance, the survey could be completed. The survey was intended to take approximately 20 minutes to complete and the Remark Web Survey software allowed respondents to stop and start if interrupted, provided an email reminder service, allowed for the respondents to go back and change their answers and provided a print-out of the completed survey.

\section{Results}

Demographics and Educational Background

Respondents consisted of 272 women from all Australian states and territories (see Table II).

\begin{tabular}{lcr}
\hline State or Territory & Number & \multicolumn{1}{c}{$\%$} \\
\hline Australian Capital Territory (ACT) & 24 & 8.8 \\
New South Wales (NSW) & 71 & 26.1 \\
Northern Territory (NT) & 10 & 3.7 \\
Queensland (QLD) & 75 & 27.6 \\
South Australia (SA) & 16 & 5.9 \\
Tasmania (TAS) & 5 & 1.8 \\
Victoria (VIC) & 40 & 14.7 \\
Western Australia (WA) & 31 & 11.4 \\
Total & 272 & 100.0 \\
\hline
\end{tabular}

Table II. Respondents by location.

More than half $(54 \%)$ of respondents came from two states, New South Wales and Queensland. In addition, more than half the respondents (55.5\%) were aged between 30 and 45 years (see Table III). All except three respondents were Australian citizens or permanent residents $(n=269)$, with $224(82.4 \%)$ having receiving their secondary education in Australia. Two hundred and eight (76.5\%) respondents had university qualifications, $28 \%$ having Masters or $\mathrm{PhD}$ degrees. In addition, 64 women $(23.5 \%)$ entered the ICT field through trade or Technical and Further Education pathways. Of those who entered the ICT profession from a non-university pathway, $68 \%(n=44)$ were aged 35 years or over. 


\begin{tabular}{lcr}
\hline Age group & Number & \multicolumn{1}{c}{$\%$} \\
\hline 25 years or less & 27 & 9.9 \\
25-29 years & 23 & 8.5 \\
30-34 years & 42 & 15.4 \\
35-39 years & 53 & 19.5 \\
40-44 years & 45 & 16.5 \\
45-49 years & 32 & 11.8 \\
50-54 years & 32 & 11.8 \\
55-59 years & 15 & 5.5 \\
60 years or over & 3 & 1.1 \\
Total & 272 & 100.0 \\
\hline
\end{tabular}

Table III. Age groups of respondents.

\section{Industries where Respondents were Employed}

Figure 2 outlines respondents' work sectors, revealing that most $(66.6 \%)$ of the respondents worked in the ICT industry.

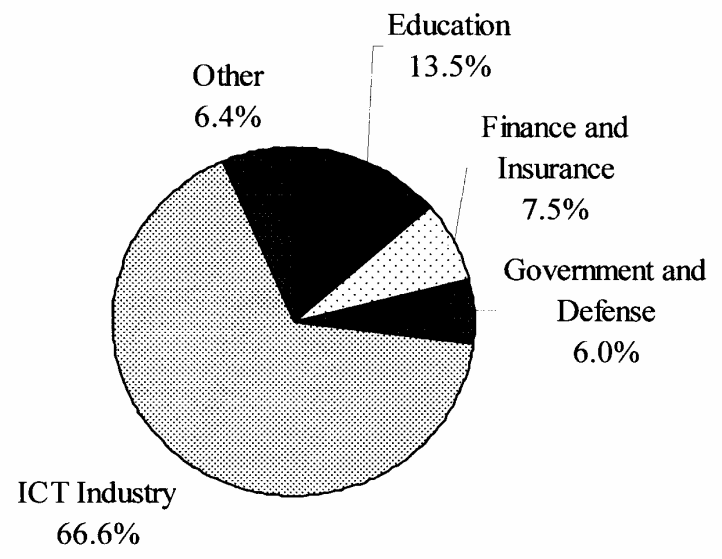

Figure 2. Distribution of respondents by industries in which they were employed.

\section{Reasons for Choosing ICT as a Career}

Principal Component Analysis. The quantitative survey questions appeared in three main subsections: C1. 'What were the main reasons you chose the ICT industry as your career path?' (17 [5point Likert] items); C4. 'Indicate your level of disagreement or agreement regarding the following qualities that may be attributed to ICT as a career for women' (14 [5-point Likert] items); and C7. 'Indicate your level of disagreement or agreement to these statements regarding masculine and feminine behaviours in the workplace and the ICT industry' (10 [5-point Likert] items, five [3-point 'yes', 'no', 'unsure'] items). To achieve a more streamlined understanding of the interrelationships between the questions in each section, the 5-point Likert items were subjected to Principal Component Analysis using SPSS. Subsequently, 41 of the Likert items were reduced to 10 variables as outlined in Table IV. Two items converged but did not achieve an acceptable alpha rating (.41). These were 'In my workplace I am confident of my technical abilities' and 'I would encourage young women/girls to enter the ICT industry', and were retained as separate variables in their own right. 


\begin{tabular}{|c|c|c|c|}
\hline Variable & $\begin{array}{c}\text { Cronbach's } \\
\text { alpha }\end{array}$ & $\begin{array}{c}\text { Number of } \\
\text { items }\end{array}$ & Highest loading item (loading) \\
\hline \multicolumn{4}{|c|}{ Section C1. What were the main reasons you chose the ICT industry as your career path? } \\
\hline Job satisfaction & .81 & 4 & ICT provides interesting work $(.86)$ \\
\hline Flexibility & .79 & 5 & ICT provides flexible working hours $(.82)$ \\
\hline Image & .77 & 5 & ICT is considered to be of 'high status' (.79) \\
\hline Social usefulness & .66 & 3 & ICT provides a responsible job $(.73)$ \\
\hline \multicolumn{4}{|c|}{$\begin{array}{l}\text { Section C4. Indicate your level of disagreement or agreement regarding the following qualities that may be attributed to } \\
\text { ICT as a career for women. }\end{array}$} \\
\hline Opportunity & .70 & 3 & There are lots of job opportunities in ICT $(.80)$ \\
\hline Reward & .63 & 4 & People respect me $(.75)$ \\
\hline Helping society & .56 & 4 & ICT provides opportunities to help others $(.76)$ \\
\hline Stereotype & .58 & 4 & Only computer 'geeks' or 'nerds' work in ICT (.66) \\
\hline \multicolumn{4}{|c|}{$\begin{array}{l}\text { Note. One item 'An ICT career is boring' loaded onto two variables, Stereotype (.39) and also onto Reward } \\
(-.55) \text { where the item was reverse scored. }\end{array}$} \\
\hline \multicolumn{4}{|c|}{ Section C7. Statements regarding masculine and feminine behaviors in the workplace and the ICT industry. } \\
\hline Equality & .80 & 6 & $\begin{array}{l}\text { In Australia, women in the ICT industry are } \\
\text { discriminated against (reverse scored) }(-.72)\end{array}$ \\
\hline $\begin{array}{l}\text { Management } \\
\text { approachability }\end{array}$ & .85 & 2 & $\begin{array}{l}\text { In my workplace, I feel or felt able to raise concerns } \\
\text { about how I have been treated }(.86)\end{array}$ \\
\hline
\end{tabular}

Note. Rotation method: Varimax with Kaiser Normalization. Rotations converged in six iterations.

Table IV. Variables obtained through Principal Component Analysis.

Pearson's correlations between the variables identified in the Principal Component Analysis are displayed in Table $\mathrm{V}$.

\begin{tabular}{|c|c|c|c|c|c|c|c|c|c|c|c|c|}
\hline & & 1 & 2 & 3 & 4 & 5 & 6 & 7 & 8 & 9 & 10 & 11 \\
\hline 1 & IMAGE & - & & & & & & & & & & \\
\hline 2 & JOB SATISFACTION & $.307^{\star \star \star}$ & - & & & & & & & & & \\
\hline 3 & SOCIAL USEFULNESS & $.276^{\star \star \star}$ & $.570^{\star \star \star}$ & - & & & & & & & & \\
\hline 4 & FLEXIBILITY & $.266^{\star \star \star}$ & $.445^{\star \star \star}$ & $.505^{\star \star \star}$ & - & & & & & & & \\
\hline 5 & REWARD & $.407^{\star \star \star}$ & $.478^{\star \star \star}$ & $.325^{\star \star \star}$ & $.224^{\star \star \star \star}$ & - & & & & & & \\
\hline 6 & OPPORTUNITY & $.338^{\star \star \star *}$ & $.352^{\star \star \star \star}$ & $.198^{\star \star}$ & $.327^{\star \star \star \star}$ & $.378^{\star \star \star}$ & - & & & & & \\
\hline 7 & HELPING SOCIETY & $.137^{\star}$ & $.587^{\star \star \star}$ & $.467^{\star \star \star}$ & $.508^{\star \star \star}$ & $.404^{\star \star \star}$ & $.332^{\star \star \star}$ & - & & & & \\
\hline 8 & STEREOTYPE & $-.175^{\star \star}$ & $-.391^{\star \star \star}$ & $-.206^{\star \star}$ & $-.221^{\star \star \star}$ & $-.616^{\star \star \star}$ & $-.346^{\star \star \star}$ & $-.346^{\star \star \star}$ & - & & & \\
\hline 9 & EQUALITY & $.042(\mathrm{~ns})$ & .047 (ns) & $.010(\mathrm{~ns})$ & $.053(\mathrm{~ns})$ & $.230^{\star \star \star}$ & $-.054(\mathrm{~ns})$ & $.088(\mathrm{~ns})$ & $-.156^{*}$ & - & & \\
\hline 10 & $\begin{array}{l}\text { MANAGEMENT } \\
\text { APPROACHABILITY }\end{array}$ & $-.010(\mathrm{~ns})$ & $.075(\mathrm{~ns})$ & $.054(\mathrm{~ns})$ & $.138^{\star}$ & $.202^{\star \star}$ & $.125^{\star}$ & $.124^{\star}$ & $-.204^{\star \star}$ & $.514^{\star \star \star}$ & - & \\
\hline 11 & $\begin{array}{l}\text { I would encourage young } \\
\text { women/girls to enter the } \\
\text { ICT industry. }\end{array}$ & $.277^{\star \star \star \star}$ & $.328^{\star \star \star \star}$ & $.183^{\star \star}$ & $.255^{\star \star \star}$ & $.370^{\star \star \star}$ & $.289^{\star \star \star}$ & $.323^{\star \star \star}$ & $-.356^{\star \star \star}$ & $.329^{\star \star \star}$ & $.286^{\star \star \star}$ & - \\
\hline 12 & $\begin{array}{l}\text { In my workplace, I feel } \\
\text { confident of my technical } \\
\text { abilities. }\end{array}$ & $.067(\mathrm{~ns})$ & $.176^{\star \star}$ & $-.036(\mathrm{~ns})$ & .069 (ns) & $.101(n s)$ & $.058(\mathrm{~ns})$ & $.054(\mathrm{~ns})$ & $-.125^{\star}$ & $.232^{\star \star \star}$ & $.184^{\star \star}$ & $.250^{\star \star \star}$ \\
\hline
\end{tabular}

${ }^{\star}$ Correlation is significant at the 0.05 level (2-tailed),

${ }^{\star \star}$ Correlation is significant at the 0.01 level (2-tailed),

${ }^{\star \star \star}$ Correlation is significant at the 0.001 level (2-tailed).

Table V. Pearson's correlations of study variables.

Cluster analysis. The variables achieved by the Principal Component Analysis process were standardized and subjected to K-means cluster analysis using SPSS. This enabled the researchers to locate and identify groups within the dataset that displayed similar response patterns (Clatworthy et al, 2005). The purpose was to explore the extent to which groupings of ICT professionals shared perceptions of the ICT industry reported in previous research, as described above.

K-means cluster analysis involves partitioning cases into $n=\mathrm{k}$ clusters, maximizing the differences between clusters and minimizing variance within clusters using Euclidean distance between cluster centers (Cortina $\&$ Wasti, 2005). The researcher requests the number of desired 
clusters. In the present study this was analyzed initially with two, three and four cluster solutions. Initial indications were that the most effective classification of respondents was in three clusters. A cross-validation procedure for cluster analysis was run twice on halves of the total sample. Convergence into three clusters was achieved in 13 iterations. Final numbers in clusters were 127 $(46.7 \%)$ in Cluster 1, $96(35.3 \%)$ in Cluster 2 and $49(18 \%)$ in Cluster 3. Table VI presents distances between final cluster centers, indicating that clustering resulted in three distinct groups.

\begin{tabular}{lll}
\hline Cluster & 1 & 2 \\
\hline $1(n=127)$ & & 1.78 \\
$2(n=96)$ & 1.78 & \\
$3(n=49)$ & 2.17 & 3.31 \\
\hline
\end{tabular}

Table VI. Euclidean distance between final cluster centers.

Notably, all groups disagreed, albeit to varying degrees, with the negative stereotypes of the ICT industry as a field populated by 'geeks' and 'nerds', and with perceptions that the work is sedentary and ICT is boring.

Figure 3 illustrates respondents in Cluster 1 and Cluster 2 agreeing on all variables, differing only in their level or strength of agreement/ disagreement.

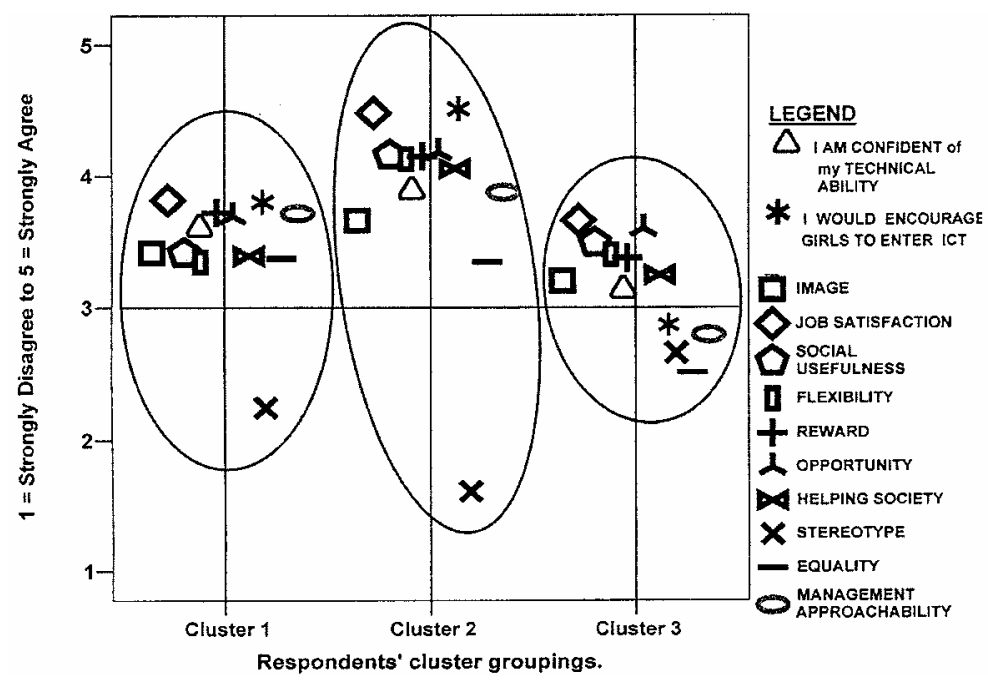

Figure 3. Symbolic representation of variable distribution within cluster groups.

Cluster 3 women agreed with Cluster 1 and Cluster 2 women on high expectations of a career in ICT (job satisfaction, social usefulness, flexibility and image), that a career in ICT provides opportunity, reward, and benefits society, and reported similar disagreement with prevailing stereotypical images of ICT. This cluster, however, disagreed with the other clusters on the measures of equality, management approachability, and whether they would encourage young girls to enter the ICT industry. In addition, Cluster 3 women were closer to the 'neither agree nor disagree' than the other two clusters of women on the variable 'I am confident of my technical abilities'.

Because of their non-numerical scale, responses to the bank of nominal 'yes', 'no', 'unsure' questions concerning workplace culture were not included in the cluster analysis. Responses to these items, which were derived from Griffiths \& Moore's (2006) WINIT survey, however, cohered very closely to the group clusters. Questions not used in the original cluster analysis that demonstrate clear differentiation between the clusters served to provide construct validation for the cluster analysis process (Clatworthy et al, 2005). Cluster 1 and Cluster 2 women disagreed that there was a culture of women being excluded from non-work socializing deemed crucial for career advancement. Conversely, almost half the Cluster 3 women reported this culture did exist (see 
Figure 4) and almost $80 \%$ of Cluster 3 women agreed that there was a workplace culture where women were held to a higher standard than their male peers (see Figure 5).

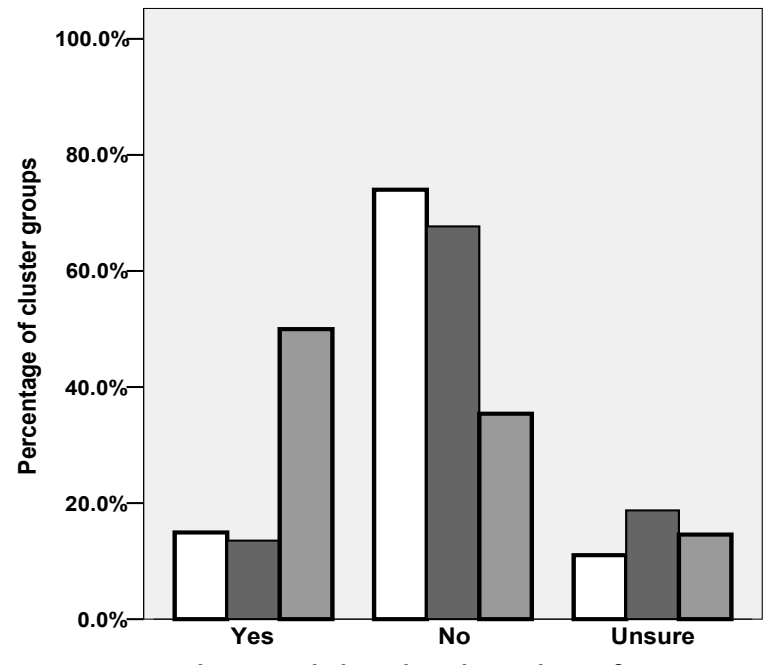

C Cluster 1
․ Cluster 2

D Cluster 3

In my workplace there is a culture of women being excluded from non-work socialising which is necessary for career advancement

Figure 4. Comparisons of clusters in response to question C6, item 1 (derived with permission from Griffiths \& Moore, 2006).
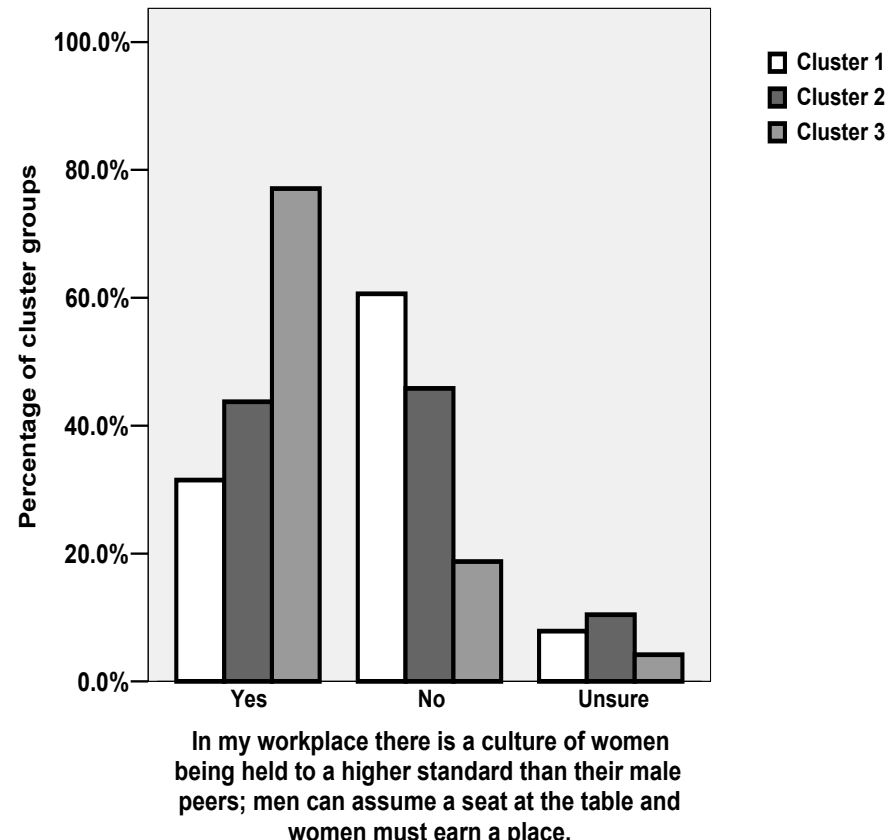

Figure 5. Comparisons of clusters in response to question C6, item 2 (derived with permission from Griffiths \& Moore, 2006).

The statistical comparison between the clusters on the bank of non-numerical items is represented in Table VII. 


\begin{tabular}{lccc}
\hline In my workplace there is a culture of... & $n$ & $\mathrm{df}$ & $\chi^{2}$ \\
\hline $\begin{array}{l}\text { 1. women being excluded from non-work socializing which is } \\
\text { necessary for career advancement }\end{array}$ & 271 & 4 & $34.78^{\star \star \star}$ \\
$\begin{array}{l}\text { 2. women being held to a higher standard than their male peers; men } \\
\text { can assume a seat at the table whereas women must earn a place }\end{array}$ & 271 & 4 & $30.92^{\star \star \star}$ \\
$\begin{array}{l}\text { 3. women experiencing blatant discrimination } \\
\text { 4. women experiencing subtle discrimination }\end{array}$ & 270 & 4 & $23.24^{\star \star}$ \\
5. women facing additional barriers in their attempts to enter the & 271 & 4 & $22.08^{\star \star \star}$ \\
male-dominated ICT world & & & \\
\hline
\end{tabular}

Note. ${ }^{\star \star} \mathrm{p}<.01,{ }^{\star \star \star} \mathrm{p}<.001$.

Table VII. Summary of statistical comparisons between the clusters on the bank of 3-point items.

\section{Qualitative Results and Discussion}

The qualitative results obtained from the survey have been integrated with the discussion in order to put these findings into perspective. Reducing the survey responses in Section C into 12 variables and then subjecting these variables to K-means cluster analysis allowed the research team to extrapolate from the dataset trends constituting the distinctive profiles of the three clusters. The following qualitative findings and discussion map the main contours of the respective clusters and elucidate these by means of respondents' own words with respect to their reasons for entering ICT, advice they would give young female recruits to the career, and the kinds of grounds on which they may have contemplated abandoning their career. This permits development of a rich sense of each cluster in its own right and in relation to others, and provides a basis for suggesting possible implications and suggestions for possible strategic responses within education and industry and possibilities for further research.

\section{Cluster 1. 'Temperate Positives'}

'Be prepared to work your butt off, while others around you snooze. However, if you work hard and make it visible you will be recognized.'

The largest cluster, Cluster $1(n=127)$, was characterized by women who were generally interested in computers, saw themselves as technically and logically proficient, began with high expectations of a career in ICT in terms of job satisfaction, social usefulness, flexibility and image, and believed a career in ICT provided opportunity, rewards and benefits to society. Cluster 1 women were satisfied in their careers, agreed that they enjoyed job equality and perceived management as approachable. Predominantly, they would strongly encourage women/girls to enter ICT and they disagreed that the ICT industry suffered from negative stereotypes. With respect to the work culture, Cluster 1 women disagreed more strongly than the women in the other clusters that they were being held to a higher standard than their male peers. They did not report feeling 'excluded from non-work socializing which is necessary for career advancement'. There was near-mirror agreement between Cluster 1 and Cluster 2 women on the theme of workplace discrimination. Both clusters disagreed strongly that there was a workplace culture of blatant discrimination but tended to slightly agree that a culture of subtle workplace discrimination was evident. Finally, Cluster 1 women tended to disagree with the statement that women faced additional barriers to entry into the male-dominated ICT industry.

Reasons for choosing ICT as a career. Fifty-six Cluster 1 women (44\%) provided short answers to question C2 (asking reasons why they chose ICT as a career), half of them reporting that they chose ICT because they enjoyed it and anticipated a rewarding career in this field. Job satisfaction was their main expectation for entering the ICT industry. Respondents had expected to be interested, challenged and provided with opportunities to expand their creativity. Typical statements were definitely positive, but moderately rather than enthusiastically or exuberantly so. Hence, one respondent said she 'found it easy and enjoyable, and much more likely to find a job 
[in] than in my other interest of astro-physics (which I was not as skilled at)'. Another said she 'simply wanted something more challenging than clerical work to allow me to use my brain! ... $[\mathrm{T}]$ here was about $2 \%$ of females in the company ICT function at that time. It simply looked like a terrific career'.

Eleven of the fifty-six respondents to this question reported getting into ICT 'by accident', which supports findings (e.g. Margolis \& Fisher, 2002; Young, 2002) that girls and young women often have insufficient or inaccurate knowledge about ICT careers. Ten women said that they had technical ability or were attracted by the logic of ICT, and five reported being influenced by others, which is a reminder of the influence others, especially parents, have on career choice (Margolis $\&$ Fisher, 2002). According to one respondent, 'I moved into IT as I was good at it ... was interested in the subjects and had a technical engineer as a father who encouraged science-based careers'.

Interestingly, of the 45 responses to question $\mathrm{C} 5$ about qualities respondents would attribute to ICT as a career for women, almost half $(n=20)$ referred to gender-related themes, most commonly observing that women were more suited to the ICT field than were men. Typical responses included, 'Women make better systems analysts as they are generally good listeners', 'Women usually bring superior communication skills to IT', and 'We don't give up. We actually finish jobs we are working on. We are more careful and think with both logic and creativity [but] can be a bit too sensitive'.

Advice to girls/women wishing to enter the ICT industry. Of the 127 respondents in Cluster 1, 106 (83\%) addressed question C8 on advice they would give young women/girls about entering the ICT industry. Responses varied between those of the large majority (65 of 106) who would strongly encourage young women to enter the field, and others who were either ambivalent $(n=30)$ or who gave a positive response counterbalanced with a negative consideration $(n=25)$.

Typical ambivalent responses included, 'Don't do it just because it pays well - do it because you want to. These sort of people are better at it and last longer', and 'I would encourage her to think creatively about the type of job she might like, e.g. maybe sales, with a vendor, as a business analyst or specialist in something she likes e.g. telecoms, security gaming. I am in two minds about encouraging young women'. Typical counterbalanced responses included 'I think it is an exciting field to be in although it does require constant retraining to maintain skills' and 'There are opportunities here but be aware of the changing goalposts, retrenchments'.

Twenty-one respondents mentioned male domination or discrimination, such as 'Try not to be put off by the industry being male dominated' and 'Girls are often better at it than boys - we just have to prove it more'.

Reasons given for contemplating leaving the ICT industry. Seventy-seven respondents (60\%) identified reasons that had led them at some time or other to contemplate leaving their ICT career. Of these, 41 referred to familiar elements of work culture and practices identified as aversive for female employees. Twelve respondents specified discrimination and office politics: 'I'm so tired of having to prove myself and having my ideas disregarded because I'm a "girly girl"', and 'The companies I worked for were dreadful in terms of discrimination against women with children'. Balancing this were several responses claiming that the ICT industry was less discriminatory towards women than other industries. For example, 'There is more anti-women feeling in other industry, in the IT world women receive a much fairer deal'. The remaining responses identified inflexible work conditions $(n=8)$, boredom $(n=6)$, stress and job frustration $(n=6)$, glass ceiling/lack of promotion $(n=5)$ and the wish for a more socially useful career $(n=4)$. These results supported previous findings (e.g. Meyerson \& Fletcher, 2000; von Hellens and Nielson, 2001; Jepson \& Perl, 2002; Margolis \& Fisher, 2002).

\section{Cluster 2. 'Enthusiastic Positives'}

'ICT can take you anywhere, ICT IS everywhere.'

The 96 women comprising Cluster 2 generally agreed on all variables with Cluster 1 women. The difference was in the level of agreement/disagreement on the variables. Cluster 2 women were more excited about computers and more enthusiastic about the ICT industry as a good career field 
offering numerous benefits. They reported the highest job satisfaction of the three clusters and agreed more strongly to social usefulness, flexibility and image and that a career in ICT provided opportunity, rewards and benefits to society. Cluster 2 women reported that they enjoyed job equality, found management approachable, were confident of their technical abilities and would encourage women/girls to enter ICT. Like Cluster 1 women, they also disagreed, although more strongly, that the ICT industry suffered from negative stereotypes. The only dimensions where Cluster 2 responses were less positive than Cluster 1 responses concerned the statements that workplace culture excluded women from non-work socializing necessary for career advancement and that women were held to a higher standard than their male counterparts. These results support previous findings (e.g. von Hellens \& Nielson, 2001; Trauth, 2002; Moore et al, 2005). As previously noted the two groups were virtually identical with respect to perceptions of discrimination. The differences between Cluster 1 and Cluster 2 women are most apparent in respondents' own words.

Reasons for choosing ICT as a career. Fifty-eight of ninety-six women (60.4\%) responded to question C2 asking why they chose ICT as their career. Almost half $(n=30)$ referred to the same kinds of reasons identified by Cluster 1 women, that they enjoyed ICT, were interested in the potential of new technologies, and that their analytical styles and technical abilities were suited to ICT. The tenor of Cluster 2 responses, however, was much more effusive. Whereas Cluster 1 responses referred to ICT as being 'enjoyable' and 'easy', typical Cluster 2 responses were more effusive: 'Working with a global team, learning about other cultures through business travels, being able to do exciting research work, working on cutting-edge technology. I love it all!', 'ICT is limited only by one's imagination ... It's great to work within a field [where] you can "create" or "develop" new systems', and experiencing 'a complete buzz when I complete a piece of code and it works'. Respondents said they were drawn to the field because it was new and innovative, and spoke of being 'attracted by the wow factor about working in ICT' where 'the possibilities are endless and fascinating'.

Advice to girls/women wishing to enter the ICT industry. Despite Cluster 2 containing 31 fewer participants than Cluster 1, more respondents (69 versus 65) to question C8 said they would strongly encourage young women/girls to enter the ICT field. Cluster 2 women's advice for young women and girls was more optimistic and enthusiastic than comments by Cluster 1 women, emphasizing the excitement and opportunities of the work. Typical responses included: 'It's exciting, you can take it anywhere, lots of opportunities to branch out into different types of ICT'; 'Go girl go ... It's an excellent career path. Great skills that are never useless in the workforce in any area at any time'; 'It's a great career'; 'A very interesting and challenging, ever changing field'; 'The ICT industry is an exciting area to work in'.

Conversely, only five Cluster 2 women (of 96), compared with 25 (of 127) in Cluster 1, provided a downside to a career in ICT. For example, 'ICT is still a new frontier for women/girls and entering is challenging but will be very rewarding particularly for girls who can ignore gender and get on with the job'. Only four Cluster 2 women, compared with 21 in Cluster 1, provided negative advice. 'Women need to be aware of the hurdles working in IT. Examples are: male staff who don't even work in the IT department try to tell you what to do when you come to fix their computer, you also tend to get babied a lot'. These results add to previous evidence that the ICT workplace is masculinized (Moore et al, 2005).

Reasons given for contemplating leaving the ICT industry. A similar proportion of Cluster 2 women $(58 \%)$ to those in Cluster $1(60.4 \%)$ responded to question C9 asking about reasons for considering leaving the industry. Interestingly, almost half the responses debunked the question, insisting they had not considered leaving the industry: 'I'm not leaving, love it'. Only 31\% $(n=24)$ reported considering leaving the industry. Reasons ranged across: industry image, 'I would like to work in an industry that is perceived as more glamorous'; technical ability, 'Having to keep up with constantly changing technology'; remuneration, 'Better pay'; boredom, 'Different challenges'; insufficient employment, 'Lack of local IT work in the area'; and family, 'To start a family'. Just four respondents identified discrimination or problems associated with working in a male-dominated industry as reasons for considering leaving the ICT industry. Other issues mentioned by Cluster 2 
respondents were long working hours, inability to progress their career (glass ceiling effect), and stress and lack of recognition were also reported, which supported previous findings (e.g. Jepson $\&$ Perl, 2002; Trauth, 2002).

\section{Cluster 3. 'Somewhat Disaffected'}

'Go away or be prepared to study harder and longer, work harder, be paid less, be treated in a generally condescending manner, be shouted down when trying to argue rationally, be asked to make coffee during a high-level negotiation.'

In stark comparison to the other two clusters, the 49 women who comprised Cluster 3 expressed disaffection with their careers. Like the others they entered the ICT industry with high expectations for job satisfaction, social usefulness and flexibility, agreed that the ICT industry provided opportunities and rewards, and disagreed, although much less strongly than the other clusters, that the ICT industry suffers from a negative stereotype. There, however, the similarities ended. They disagreed that there was equality in the workplace, reporting more overt and subtle discrimination than women in the other two clusters, and frustration at their inability to progress their careers. Almost half the Cluster 3 women agreed with the statement 'In my workplace there is a culture of women being excluded from non-work socializing which is necessary for career advancement', and almost $80 \%$ agreed that 'In my workplace there is a culture of women being held to a higher standard than their male peers; men can assume a seat at the table and women must earn a place'. Another 35\% reported 'blatant discrimination' and $82 \%$ subtle discrimination. They lamented a 'long hours' culture, lack of balance between work and wider life, which resonated with findings reported by Jepson \& Perl (2002). Cluster 3 women also reported experiencing unremitting pressure to perform, and a sense that they were continually subjected to unfavorable and unfair comparisons with their male colleagues.

Cluster 3 respondents reported in numbers difficulties with management approachability and/or an inability to discuss grievances. Unlike Cluster 1 and Cluster 2 respondents, Cluster 3 women felt undervalued by their organizations, would not recommend the ICT industry to young women/girls and many had considered leaving their career. By contrast with the other clusters, Cluster 3 women only slightly agreed that the ICT industry had a good image and helped society, and hovered almost at the undecided line on confidence in their own technical ability.

Reasons for choosing ICT as a career. Cluster 3 women entered the field of ICT with similar expectations to the other clusters (anticipating job satisfaction and a rewarding career that would be socially useful). Reasons included technical ability, 'I am good at it', and the field suiting their logical or analytical areas of expertise, 'Focuses on problem solving, logical, structured'. One respondent said, 'I am a compulsive tinkerer and always like to know how things work. I was caught up in the Internet boom [in 1994] and was one of the few people that saw the potential very early on'. Others conceded falling into their careers: 'Got into ICT purely by accident, because I could type, I had no previous ICT knowledge or interest in the area'; 'Only place I could get a job after I completed my PhD in Zoology'.

Advice to girls/women wishing to enter the ICT industry. Ninety percent $(n=45)$ of respondents provided responses to question C8 about advice to young women/girls entering the ICT industry. Only five would strongly encourage women/girls to enter ICT. Their responses, however, were not effusive: 'I think ICT is a good field to be into. It's not all about computers'; 'It provides an interesting and challenging work life that is rarely boring'; 'Go for it, has lots of opportunities and it is not just about geeky technology'.

Seven women (16\%) offered positive advice tempered by a negative downside. For example, 'Make sure you love it. Make sure you're willing and able to justify yourself ALMOST every step of the way'; 'The industry itself is good to work in but you must be very careful about choosing a company"; "Boys' jobs" pay more - you'll almost always get paid more than "girls' jobs”. ICT is everywhere, it's not going away and it's in every industry. Don't let the $\mathrm{b}^{\star}$ stards [sic] grind you down - keep perspective, you ${ }^{\star} \mathrm{can}^{\star}$ do it, no matter what anyone says’. 
The largest subset of responses $(n=17$ or $38 \%)$ offered negative advice articulating the disillusionment Cluster 3 women generally felt about ICT careers. One respondent said, 'I couldn't recommend ICT and am actively discouraging my 14-year-old son from entering the ICT industry'. A second responded, 'Don't even bother with the industry, they should study finance instead. Knowing what I know now, I wouldn't have done engineering at all'.

Cluster 3 women also expressed, in ways the other clusters did not, the difficulties of trying to merge family commitments with a career involving long hours and inflexible schedules. Typical responses included: 'This is not a 9-5 career, so if you plan on having a family it can get tough'; 'This is not a flexible industry. There are little or no job opportunities for flexible, part-time working hours should she wish to work them after having children'; 'Not worth the effort, if you want kids go teaching and get longer holidays to enjoy with your children'. These comments again provide further evidence of lack of balance between work and family reported as a barrier for women by Jepson \& Perl (2002). This cluster was much more pessimistic than the other clusters about ICT as a profession. Their responses resonated strongly with previous findings that the ICT industry is unattractive to women with respect to their contributions being undervalued (Woodfield, 2002) and to being held to a higher standard (Trauth, 2002).

Reasons given for having contemplated leaving the ICT industry. Seventy-six percent of the cluster $(n=$ 37) responded to question C9. Fourteen respondents identified discrimination issues, targeting negative consequences of discriminatory practices. Some spoke of a 'male-dominated industry' with 'pressure to prove yourself or even be heard'. The "Boys club" still exists no matter what people say and how much you try to work around it'. Others observed, 'treatment by immediate male colleagues who overtly or inadvertently exclude "others" from the decision process'. Several respondents alluded to the 'glass ceiling' as a source of career frustration, as they were prevented from advancing their careers. Typical examples included: 'Discrimination. The "mates club". No chance of promotion'; 'Getting ignored for every available promotion when I am more than qualified and it is getting very discouraging'; 'Upset when yet again passed over for a dill who thinks he's my equal (when he has less experience, less know how and fewer quals [sic])'.

A further 13 responses reported long hours, workload, stress, inflexible work hours and burnout as reasons for considering a job change. For example: 'Burnt out and tired of being viewed by the business side of corporations as the bad IT guys who never deliver'; 'Workload, sickness, management decisions, frustration caused by management decisions'; 'Long and unpredictable hours, too much travel, stressful, caused health issues. Requests to work from home 1 day a week, and/or to work part-time denied'.

\section{Summary of Findings}

The study aimed to map and describe insider perspectives in relation to outsider perceptions of ICT careers and the ICT industry from the standpoint of four specific purposes, three of which pertain directly to our focus in this article. Substantial findings can be reported for each of these three purposes, which we will address in turn.

\section{To Provide a Local Index of the Corrigibility of Stereotypes and}

Public Perceptions Concerning the ICT Industry and ICT Careers

Most respondents entered ICT careers via university studies with a sense of performing socially useful work (e.g. 'doing work that benefits society' and 'contributing to the social good'), which was also critically important to the high school girls' career aspirations to 'work with people, not machines' and contribute to 'socially useful projects'. For the most part the women ICT professionals reported expectations that this career would provide job satisfaction, flexibility and a good social image. The experiences of most were in line with their expectations. They generally agreed that a career in ICT is rewarding and provided challenges and opportunities. Most shared a sense of reward in terms of enjoying community respect, finding their work interesting, meeting interesting people and being well remunerated. Most likewise saw themselves as having good 
opportunities and considered their work as providing benefits to society. To this extent the findings demonstrate the corrigibility of stereotypes and public perceptions of ICT careers and the industry.

To Map the 'Reality' of Insider Perspectives in Relation to

Specific Beliefs Espoused by the Queensland Student Participants

Views across all three clusters, including those from Cluster 3, negated widespread negative stereotypes and public perceptions echoed by many of the female student respondents previously surveyed that ICT is boring, sedentary and populated by 'geeks' and 'nerds'. The findings provide the strongest possible grounds for claiming that the Queensland students in this sample held beliefs about ICT careers that ran directly counter to the lived work experiences of professional-industry women, even including those most disaffected in their jobs. There indeed are aspects of the ICT industry and career that many women find genuinely aversive. These did not, however, include the reasons proffered by student informants about why they did not entertain ICT as a career prospect.

\section{To Identify and Describe Any Diversity and Complexity in Experiences and}

Perspectives Apparent Within the Survey Population of Women ICT Professionals

The findings speak in greatest depth to the third purpose of the research aim. Groups clustering within the industry survey population differed significantly from each other in their career experiences. Variables that showed the most inconsistency were equality, management approachability, confidence in technical ability, and whether respondents would encourage young women to enter the industry. Variability between clusters, as well as subsets of responses within each cluster, nonetheless resonated with a range of factors identified in existing research literature to be experienced as aversive by women ICT professionals.

Clustering the large group of respondents provided an opportunity to look more closely at specific factors that provided evidence that different subgroups have distinctly dissimilar workplace experiences and that subtle combinations of factors may work in combination to create an alienating workplace environment, such as that reported by Cluster 3 women, making this group at risk of leaving the industry and dissuading these women from promoting the ICT industry to young women/girls who might consider entering the ICT profession.

Viewing the ICT women's responses from the standpoint of clusters has indicated that female ICT professions in no way comprise an amorphous or homogenous group. Distinctive differences between the clusters, based on their experiences in the industry, resemble peeling an onion; one layer is removed only to uncover more layers that are more intricate and require careful consideration. Following this complexity more deeply, such as by looking within some groups (e.g. ICT industry women in isolation) and across particular groups, such as looking at groups based on kind of work (e.g. programmers versus systems analysts), is the direction of continuing analysis and subsequent publications. It is expected that this will further illuminate factors associated with low participation rates of females in ICT.

The findings generally support and extend a number of previous research studies (Meyerson $\&$ Fletcher, 2000; Cuny \& Aspray, 2002; von Hellens \& Nielsen, 2002; Woodfield, 2002; Armstrong, 2005; Griffiths \& Moore, 2006; Cohoon \& Aspray, 2006) by demonstrating a correlation between management approachability and a sense of equality in the workplace. It is also noted that the distribution of these two variables was accompanied by similar trends in respondents' confidence in their technical ability and their intention to encourage young women to enter the industry. The codistribution of these variables clearly demonstrated in the cluster analysis approach indicates that a more sustained investigation in future studies may well provide greater elucidation of the issues in the ICT industry that are relevant to the retention of valuable workers within it and to the possibility of attracting more workers in the future.

\section{Limitations of the Study}

Because the survey did not collect data from respondents about the size of the organizations that employed them, comparisons and contrasts were not possible between small, medium and large 
organizations. Furthermore, the type of management structure and management style was not investigated. Both areas may provide fruitful sectors of exploration in trying to unravel the complex issues surrounding women's experiences and perceptions of ICT as a desirable career path.

While the aim of this nation-wide survey was to gain perspectives from women in the ICT industry from all Australian states and territories, a representative sample was neither sought nor achieved. However, as professional women's ICT associations were specifically targeted, the researchers are satisfied that the population of respondents is probably quite typical. Nevertheless, generalizing the results to all professional women in the Australian ICT industry is not prudent.

Interviews and/or focus groups comprising women who participated in the Women in ICT Industry Survey would have added valuable in-depth insights into the current and retrospective perceptions with respect to ICT as a professional career. Use of interviews or focus groups could further illuminate important issues the present study can only gesture toward - for all their coherence with a larger national and international research corpus.

\section{Some Implications of the Findings for Policy Futures in Education and Industry}

The findings summarized above, and the discussion of survey results preceding them, suggest a range of policy directions worth pursuing on the part of schools, education systems and industry. Four lines of development seem especially promising.

\section{Pursue 'Situated' and 'Expert-like' Approaches to Educational Computing and Technology Use}

A clear message in the findings is that the kinds of situated and expert-like computing experienced by women ICT professionals is challenging, exciting, rewarding and compelling. It is so much so that many employees lose themselves in their work to the point that they may work themselves into the ground. This is a common experience among professionals who experience realization in their work (Gee, 2007). It is, of course, also an everyday experience for many young people pursuing interests and purposes mediated by ICT, whether in gaming, weblogging, building and inhabiting virtual worlds, making machinima movies, programming robots, or remixing music and images to create music videos or 'trailers'. But it is rarely experienced in classroom-based work with ICT.

The larger project in which this survey component was embedded provided strong evidence that girls became turned off by educational computing during the junior high years. This is the very point at which career decisions are beginning to be considered; where young people start thinking about their futures. This suggests the importance of pursuing policies that emphasize situated and expert-like educational computing. Contemporary technologies in the form of simulations and virtual worlds, as well as networked computing that facilitates team-based work with experts and peers anywhere in the world, can readily be appropriated to offer rich professional-like opportunities to integrate computing into mature forms of situated practice. Gee (2007) argued that computer games provide opportunities on an everyday informal basis for 'deep learning' in such professional roles as being a soldier, yet there is no Full Spectrum Scientist or Full Spectrum Data Analyst equivalent to the gaming world's Full Spectrum Warrior (p. 16, see also pp. 67-82).

While there is much more to educational learning than merely emulating the expertise and situated competence involved in the work world, there are nonetheless important overlaps. The challenge and excitement expressed by participants in the women's survey are not especially about 'computing' per se. Rather, they are about knowledge, problem solving, design, experimentation, productive collaboration, accuracy, theorizing, and many other things that education should be about. Designing learning opportunities that maximize fidelity to expertise and 'professional-like' situated practice is integral to bringing these virtues into school learning and, in the process, enhancing interest in that learning itself and in using the tools that mediate it. 


\section{Promote More Accurate ICT Careers-Related Information}

The findings add depth to recommendations forwarded by Cuny \& Aspray (2000) for attracting more women into graduate ICT degrees, such as informing undergraduates about the possible opportunities and rewards of an ICT career and actively countering negative stereotypes and misrepresentation about the industry. At the junior high and high school levels, the notion that ICT is boring and irrelevant can be partially addressed by providing positive women role models who transcend the perception that females have limited opportunities in ICT and are frequently relegated to basic clerical or data-entry jobs (Jepson \& Perl, 2002). Partnerships between industry and schools could bring the considerable 'good news' about women's ICT careers to the attention of students and those others whose conscious and unconscious expressions of opinion help shape decisions about careers, pathways and subject choices.

The complexity of interrelated factors that contribute to the underrepresentation of girls in computing, which have been clearly articulated by Barker \& Aspray (2006), such as influence of peers, life aspirations, influence of family and community, all need to be factored into designing policies and concrete initiatives to redress this problem.

\section{Put the 'Bad News' to Productive Use in Course Development and School-Industry Collaborations}

Even the 'bad news' expressed by the survey informants could be put to productive educational use by informing programs in ways that could contribute to building a vibrant ICT industry that would be more attractive to women. For example, ICT courses could include elements that encourage female students to interact with the kinds of conditions they may subsequently face in employment, thereby preparing them to make constructive, strategic responses to improve the ICT workplace environment for women. Similarly, ICT programs in schools and tertiary institutions might incorporate dimensions that would prepare students for starting their own businesses should the need arise or, alternatively, be run in tandem with courses in business studies that focus on creating and building an ICT business. Here again, contemporary ICT provides resources of great sophistication for projecting learners into virtual worlds in which authentic problems and roles can be played out, as well as enabling learners to participate in real-world/realtime contexts at distance through virtual conferencing and similar formats.

\section{Conclusion}

The Women in ICT Industry Survey provides evidence directly relevant to tackling the contemporary issue of low and declining rates of female participation in ICT professional-level careers and academic pathways leading to such careers. Findings suggest a range of policy initiatives that might usefully be pursued at high school and tertiary education levels.

\section{References}

American Association of University Women Educators (2000) Tech-savvy: educating girls in the new computer age. Washington, DC: American Association of University Women Educational Foundation.

Anderson, N., Lankshear, C., Courtney, L. \& Timms, C. (2006) Girls and ICT Survey: initial findings, Curriculum Leadership, 4(16). http:/ / cmslive.curriculum.edu.au/leader/ default.asp?id=13812

Anderson, N., Lankshear, C., Timms, C. \& Courtney, L. (2006) 'Because it's Boring, Irrelevant and I Don't Like Computers': why high school girls avoid professionally-oriented ICT subjects, Computers and Education, 50(4), 1304-1318. http:// dx.doi.org/10.1016/j.compedu.2006.12.003

Armstrong, J. (2005) Is IT Unfriendly to Women? http: / / techrepublic.com.com/ 5102-10878-5753934.html

Australian Bureau of Statistics (2006) Department of Communications, Information

Technology and the Arts, Building Australian ICT Skills. http://www.dcita.gov.au/data/assets/pdf_file/40270/Building_Australian_ICTskills.pdf

Barker, L.J. \& Aspray, W. (2006) The State of Research on Girls and IT, in J. McGrath Cohoon \& W. Aspray (Eds) Women and Information Technology: research on underrepresentation, 3-54. Cambridge, MA: MIT Press. 
Beyer, S. \& DeKeuster, M. (2006) Women in Computer Science or Management Information Systems Courses: a comparative analysis, in J. McGrath Cohoon \& W. Aspray (Eds) Women and Information Technology: research on underrepresentation, 323-349. Cambridge, MA: MIT Press.

British Computer Society (2005) Attitudes of Girls Aged 13-17 to a Career in ICT: findings. http:/ / www.bcs.org/upload/pdf/ girlsandit.pdf

Charles, M. \& Bradley, K. (2006) Female Underrepresentation in CS Programs Cross-nationally, in J. McGrath Cohoon \& W. Aspray (Eds) Women and Information Technology: research on underrepresentation, 183-203. Cambridge, MA: MIT Press.

Clatworthy, J., Buick, D., Hankins, M., Weinman, J. \& Horne, R. (2005) The Use and Reporting of Cluster Analysis in Health Psychology: a review, British Journal of Health Psychology, 10, 329-358. http: / / dx.doi.org/10.1348/135910705X25697

Cohoon, J.M. (1999) Departmental Differences Can Point the Way to Improving Female Retention in Computer Science, paper presented at the SIGCSE Technical Symposium on Computer Science Education, 24-28 March, New Orleans.

http: / / delivery.acm.org/ 10.1145/300000/299753/p198cohoon.pdf?key1=299753\&key2=0994696811\&c oll=GUIDE $\& \mathrm{dl}=$ GUIDE,ACM $\&$ CFID $=11111111 \&$ CFTOKEN=222222

Cohoon, J.M. (2001) Towards Improving Female Retention in the Computer Science Major, Communications of the ACM, 44(5), 108-114.

http: / / delivery.acm.org/10.1145cohoon.pdf?key1=374367\&key2=6584696811\&coll=GUIDE $\&$ dl=GUI DE $\&$ CFID $=26578307 \&$ CFTOKEN $=40415758$

Cohoon, J.M. (2006) Just Get Over it or Just Get On with it: retaining women in undergraduate computing, in J. McGrath Cohoon \& W. Aspray (Eds) Women and Information Technology: research on underrepresentation, 205-237. Cambridge, MA: MIT Press.

Cohoon, J.M. \& Aspray, W. (Eds) (2006) Women and Information Technology: research on underrepresentation. Cambridge, MA: MIT Press.

Coonan, H. (2005a) Women in ICT Summary Advisory Group Established. 8 March. http://www.minister.dcita.gov.au/media_releases/women_in_ict_summit_advis

Coonan, H. (2005b) Opening Address: PartICipaTion Summit 2005. 22 September. http:/ / www.minister.dcita.gov.au/media/speeches/participation_summit_2005_opening_address

Cortina, L.M. \& Wasti, S.A. (2005) Profiles in Coping: responses to sexual harassment across persons, organizations, and cultures, Journal of Applied Psychology, 90(1), 182-192. http: / / dx.doi.org/10.1037/0021-9010.90.1.182

Courtney, L., Anderson, N., Lankshear, C. \& Timms, C. (2007) Negotiating the Twisted, Broken and Sometimes Hidden Pathways to ICT Careers, Redress, Journal of the Association of Women Educators, 16(3), 14-20.

Courtney, L., Timms, C. \& Anderson, N. (2006) 'I Would Rather Spend Time With a Person Than a Machine': qualitative findings from the Girls and ICT Survey, paper presented at the 3rd National QualIT 2006 Quality and Impact of Qualitative Research Conference, Brisbane, 27-29 November.

Cuny, J. \& Aspray, W. (2002) Recruitment and Retention of Women Graduate Students in Computer Science and Engineering: results of a workshop organized by the Computing Research Association, San Francisco, June 21-22, 2000, SIGCSE Bulletin, 34(2), 168-174. http: / / dx.doi.org/10.1145/543812.543852

Department of Communications, Information Technology and the Arts (2006) Building Australian ICT Skills, presentation to the Australian Council of Professors and Heads of Information Systems, Commonwealth of Australia, 26 September, Canberra.

Department of Immigration and Citizenship (2007) Is Your Occupation in Demand? Migration Occupations in Demand. http: / / www.immi.gov.au/skilled/general-skilled-migration/ skilled-occupations/ occupations-in-demand.htm

Frieze, C. (2005) Diversifying the Images of Computer Science: undergraduate women take on the challenge! paper presented at the Special Interest Group of Computer Science Education '05 (SIGCSE), St Louis, 23-27 February.

Gee, J. (2007) Good Video Games and Good Learning: collected essays on video games, learning and literacy. New York: Peter Lang.

Griffths, M. \& Moore, K. (2006) The Women in IT (WINIT: final report). Manchester: University of Salford.

Griffiths, M., Moore, K. \& Richardson, H. (2008) Celebrating Heterogeneity? A Survey of Female ICT Professionals in England, Information, Communication \& Society, 10(3), 338-357.

http: / / dx.doi.org/10.1080/13691180701409945 
Jepson, A. \& Perl, T. (2002) Priming the Pipeline, SIGCSE Bulletin, 34(2), 36-39. http:/ / dx.doi.org/10.1145/543812.543826

Kahle, J. \& Schmidt, G. (2004) Reasons Women Pursue a Computer Science Career: perspectives of women from mid-sized institutions, Journal of Computer Sciences in Colleges, 19(4), 78-89.

Margolis, J. \& Fisher, A. (2003) Unlocking the Clubhouse: women in computing. Cambridge, MA: MIT Press.

Meyerson, D.E. \& Fletcher, J.K. (2000) A Modest Manifesto for Shattering the Glass Ceiling, Harvard Business Review, 78(1), 127-136.

Millar, J. \& Jagger, N. (2001) Women in ITEC Courses and Careers. London: Department of Education and Skills, Department for Employment. The Women's Unit: 156.

Moore, K., Griffiths, M. \& Richardson, H. (2005) Moving in, Moving up, Moving out? A Survey of Women in ICT, paper presented at Symposium on Gender and ICT: Working for Change, Manchester, February. http:/ / www.isi.salford.ac.uk/gris/wini/

National Science Foundation (2002) The Council of Graduate Schools, CGS/ GRE Graduate Enrollment and Degrees: annual surveys from 1992-2002. http:// webcaspar.nsf.gov/

Newmarch, E., Taylor-Steele, S. \& Cumpston, A. (2000) Women in IT - what are the barriers? Conference paper presented to the Network of Women in Further Education Conference Net Gains: Women, Information Technology and Emerging Issues. 20-22 March, Melbourne. http: / / www.dest.gov.au/research/pubs/ womeninit.htm

Organisation for Economic Co-operation and Development (2004) Online Education

Database. http:/ / www1.oecd.org/scripts/cde/ members/EDU_UOEAuthenticate.asp

Oudshoorn, N., Rommes, E. \& Stienstra, M. (2004) Configuring the User as Everybody: gender and design cultures in information and communication technologies, Science, Technology \& Human Values, 29(1), 30-63. http: / / dx.doi.org/10.1177/0162243903259190

Queensland Studies Authority (2007) Queensland Studies Authority Annual Report 2006-2007. http:/ / www.qsa.qld.edu.au/downloads/about/qsa_annual_report_06-07.pdf

Ridgeway, C.L. \& Correll, S.J. (2004) Unpacking the Gender System: a theoretical perspective on gender beliefs and social relations, Gender and Society, 18, 510-531. http:/ / dx.doi.org/10.1177/0891243204265269

Rommes, E., Overbeek, G., Scholte, R., Engels, R. \& de Kemp, R. (2008) 'I'm not Interested in Computers': gender-based occupational choices of adolescents, Information, Communication \& Society, 10(3), 299-319. http: / / dx.doi.org/10.1080/13691180701409838

Timms, C., Courtney, L. \& Anderson, N. (2006) Secondary Girls' Perceptions of Advanced ICT Subjects: are they boring and irrelevant? Educational Computing, 21(2), 3-8.

Trauth, E.M. (2002) Odd Girl out: an individual differences perspective on women in the IT profession, Information Technology and People, 15(2), 98-118. http:/ / dx.doi.org/10.1108/09593840210430552

Von Hellens, L. \& Nielsen, S. (2001) Australian Women in IT, Communications of the ACM, 44(7), 46-52. http: / / dx.doi.org/10.1145/379300.379310

Weber, R.P. (1990) Basic Content Analysis, 2nd edn. Newbury Park: Sage.

Woodfield, R. (2002) Women and Information Systems Development: not just a pretty (inter)face? Information Technology and People, 15(2), 119-138. http:/ / dx.doi.org/10.1108/09593840210430561

Young, J. (2002) Women in IT Tasmania Report: increasing the participation of women in information communication technology. http:/ / acs.org.au/tas/wiit/

Zweben, S. \& Aspray, W. (2004) 2002-2003 Taulbee Survey: undergraduate enrollments drop: department growth expectations moderate, Computing Research News, May, 5-19.

LYN COURTNEY is a registered psychologist and the Senior Research Associate working in the Rural Education Centre at James Cook University while completing her PhD into successful ageing of Australian baby boom career women. Lyn worked on the 2004-2006 ARC Linkage Grant 'Girls and ICT' and the current 2008-2010 ARC Linkage grant investigate the upper middle school 'turn off. Lyn is an Adjunct Lecturer in the School of Education and an Associate Lecturer in the School of Psychology teaching in Australia and Singapore. She is the ICT Coordinator for the Queensland Hub of the Centre for Science, Information and Communication (ICT), and Mathematics Education in Rural and Regional Australia (SiMERR). Correspondence: Lyn Courtney, School of 
Psychology, James Cook University, PO Box 6811, Cairns, Queensland 4870, Australia (lyn.courtney@jcu.edu.au).

COLIN LANKSHEAR is the Professor of Literacy and New Technologies at James Cook University, Australia. He also does consultant teaching in Canada. He writes extensively with Michele Knobel in the area of digital technologies and new literacies. Their recent books include 'New Literacies: Everyday Practices and Classroom Learning' (2006), 'A New Literacies Sampler' (2007), and 'Digital Literacies: Concepts, Policies and Practices' (2008). He is also joint editor of 'The Handbook of Research on New Literacies' (2008), and co-editor of the journal e-Learning. Correspondence: colin.lankshear@jcu.edu.au

NEIL ANDERSON is the Pearl Logan Chair in Rural Education at James Cook University, Australia. Prior to this appointment, Professor Anderson was deputy head of the School of Education for five years. His research has focused on ICT as means to improve educational outcomes and equity (particularly involving rural education and gender issues) and received the university award for 'Research Supervision Excellence' in 2005. He is leader of the 'Wired' research community for the multi-university research consortium 'Eidos'. He in a member of the international advisory board of 'Asia Pacific Leaders in Education' conference and serves on the editorial boards of journals such as Australian Education Researcher and Australian Educational Computing. He has published widely in high quality journals and is the author of 'Equity and Information Communication Technologies (ICT) in Education’ published by Peter Lang, New York in 2009. Correspondence: neil.anderson@jcu.edu.au

CAROLYN TIMMS is currently a Research Fellow at the Social and Organisational Psychology Research Unit (SOPRU) at Griffith University in Brisbane, Australia. She worked on the 2004-2006 ARC Linkage Grant. Prior to her academic career Carolyn had a rewarding career as a high school teacher which she left in 2003 to undertake Honours and then PhD studies in psychology at James Cook University. Her part-time employment (from 2005 to 2007) as a Senior Research Officer on the 'Girls and ICT' project enabled her to combine her previous experience in education with her research and writing skills, and to confirm her love of research. The final stage of the Girls and ICT project involved the 'Professional ICT Women National Survey'. Carolyn's expertise in organisational psychology theory and practice was invaluable for data analysis coming from this stage of the research. Correspondence: carolyn.timms@griffith.edu.au 